\title{
Immunoblastic lymphoma presenting with syncope due to sinoatrial node disease
}

\author{
G. Dolan, A.P. Jones and J.T. Reilly. \\ Department of Haematology, Northern General Hospital, Herries Road, Sheffield S5 7AJ, UK.
}

\begin{abstract}
Summary: A 68 year old man presented with syncope associated with episodes of sinus arrest. He responded to insertion of a demand pacemaker. During investigation he was noted to have generalized lymphadenopathy and biopsy revealed that he had an immunoblastic lymphoma. Before further assessment could be made, he developed rapid atrial fibrillation, resistant to several anti-arrhythmic agents and died several days after admission. At autopsy a nodular plaque of lymphoma was found to overly the sinoatrial node which was markedly fibrosed with evidence of lymphomatous infiltration of the surrounding microvasculature.
\end{abstract}

\section{Introduction}

Cardiac involvement by lymphoma is well recognized but is usually asymptomatic. The unusual presentation described in this case illustrates the importance of considering the possibility of metastases when new symptoms of cardiac disease arise in patients with lymphoma, as therapeutic intervention may be possible.

\section{Case report}

A 68 year old man presented with a 2-month history of blackouts lasting 10-15 seconds. On examination he was in sinus rhythm with a blood pressure of $130 / 70 \mathrm{mmHg}$. He was noted, however, to have generalized lymphadenopathy, hepatosplenomegaly and a widespread maculopapular rash. Resting electrocardiograph, electrolytes and liver function tests were normal but he had a normochromic, normocytic anaemia of $82 \mathrm{~g} / 1$.

During admission for further investigation, including lymph node biopsy, he suffered an acute, transient episode of unconsciousness associated with extreme pallor, pupillary dilatation and disappearance of peripheral pulses. The patient made a spontaneous, complete recovery within 10 seconds. A provisional diagnosis of Stokes-Adams attack was made and urgent 48 hour electrocardiogram (ECG) monitoring was arranged. Two similar episodes occurred during the next $\mathbf{4 8}$ hours, both were shown to coincide with short episodes of sinus

Correspondence: G. Dolan M.B., Ch.B., M.R.C.P. Accepted: 3 January 1990 arrest. He thus had a permanent demand pacemaker implanted and no further episodes occurred.

A diagnosis of immunoblastic lymphoma was made from lymph node biopsy but before further assessment could be arranged, the patient developed paroxysmal rapid atrial fibrillation associated with hypotension. These episodes of fibrillation became prolonged and failed to respond to intravenous digoxin, verapamil or amiodarone infusion. The patient developed progressive cardiac and renal failure and despite intensive support measures he deteriorated rapidly and died several days after admission.

At autopsy, there was marked intra-abdominal lymphadenopathy and also involvement of the kidneys and heart by lymphoma. Closer examination of the heart revealed that there was a $1.5 \mathrm{~cm} \times 1 \mathrm{~cm}$ lymphomatous plaque on the epicardial surface of the heart and a $1 \mathrm{~cm} \times 1 \mathrm{~cm}$ plaque on the superior vena cava. There was a $1 \mathrm{~cm} \times 1 \mathrm{~cm}$ nodular deposit of lymphoma overlying the sinoatrial (SA) node (Figure 1). Histological sections through this area showed that, although there was no evidence of direct invasion of the neural tissue by lymphoma, there was a diffuse infiltrate of malignant cells in the tissue and small blood vessels surrounding the SA node (Figure 2), which was markedly fibrosed. The coronary arteries showed only a modest degree of atheroma and there was no other significant evidence of ischaemic heart disease.

These appearances were felt to be compatible with local ischaemic damage to the SA node due to diffuse involvement of the surrounding microvasculature. 


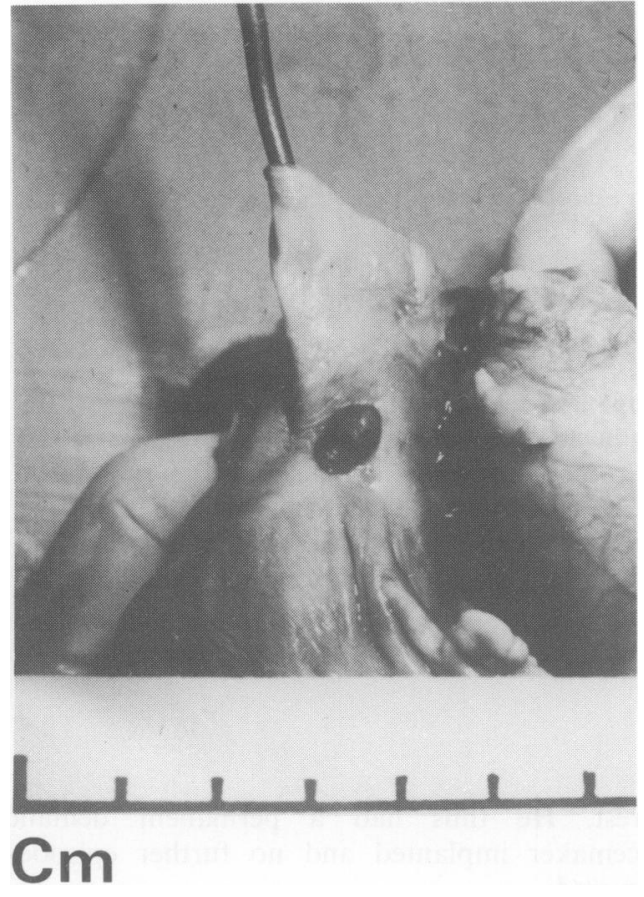

Figure 1 Showing nodular deposit of lymphoma overlying the SA node.

\section{Discussion}

Metastatic tumours of the heart are more common than primary tumours. ${ }^{1,2}$ Bronchogenic and breast carcinomas, malignant melanomas and lymphomas are those which more commonly give rise to cardiac involvement. ${ }^{3}$

A study of 196 patients dying with lymphoma found that 48 had evidence of cardiac involvement. ${ }^{4}$ Analysis of the various subtypes of lymphoma revealed that $16 \%$ of Hodgkin's disease, $25 \%$ of non-Hodgkin's lymphoma and $33 \%$ of cases of mycosis fungoides had metastatic disease of the heart. The majority of cases of secondary lymphoma of the heart are clinically silent. The most common clinical manifestation appears to be pericardial effusion with tamponade. ${ }^{1}$ Although a variety of rhythm disturbances including atrial tachycardias $^{1,5}$ and heart block ${ }^{6,7}$ have been described, these may be more commonly due to associated factors such as electrolyte disturbance, hypoxia or cardiotoxic chemotherapy. ${ }^{4}$

Cardiac dysfunction due to secondary lymphoma is very rarely the presenting feature of the disease. ${ }^{1,2}$ Cole et al. ${ }^{7}$ described a boy with Burkitt's lymphoma who presented with complete heart block associated with atrioventricular node involvement and Goggio et al. ${ }^{8}$ described a case of Hodgkin's disease presenting with Stokes-Adams syndrome.

We present the unusual presentation of immunoblastic lymphoma with syncope associated with sinus arrest due to ischaemic damage and fibrosis of the sinoatrial node. Involvement of the sinoatrial node associated with rhythm disturbance has been previously noted in non-Hodgkin's lymphoma, ${ }^{5}$ though not, to our knowledge, as a presenting feature.

It is important to consider the possibility of secondary cardiac involvement in those patients with malignant disease who have evidence of cardiac dysfunction. Treatment with antiarrhythmic therapy may be unsuccessful in such cases, although response to cytotoxic therapy may, at least in theory, be possible.

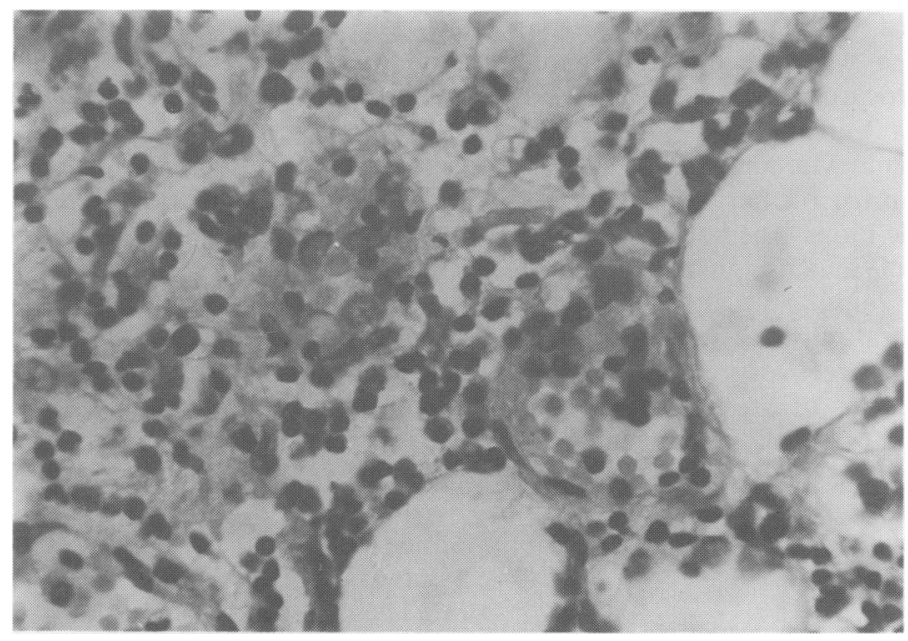

Figure 2 High power view showing a diffuse infiltrate of immunoblastic lymphoma in the myocardium around the SA node. A small blood vessel is also infiltrated. (H \& $\mathrm{E} \times 625)$. 


\section{References}

1. Rosenthal, D.S. \& Braunwald, E. Haematologic-oncologic disorders and heart disease. In: Braunwald, E. (ed) Heart Disease. A Textbook of Cardiovascular Medicine. W.B. Saunders, Philadelphia, 1987, pp. 1734-1757.

2. Hall, R.J. \& Cooley, D.A. Neoplastic heart disease. In: Hurst, J.W. (ed) The Heart. McGraw-Hill, New York, 1982, pp. $1403-1424$

3. Kapoor, A.S. Clinical manifestations of neoplasia of the heart. In: Kapoor, A.S. (ed) Cancer and the Heart. Springer-Verlag, New York, 1986, pp. 21-25.

4. Roberts, W.C., Glancy, D.L. \& De Vita, V.T. Heart in malignant lymphoma (Hodgkin's disease, lymphomosarcoma, reticulum cell sarcoma and mycosis fungoides): a study of 196 autopsy cases. Am J Cardiol 1968, 22: 85-107.
5. Allen, D.C., Allerdice, J.M., Morton, P., Mollan, R.A.B. \& Morris, T.C.M. Pathology of the heart and conduction system in lymphoma and leukaemia. J Clin Pathol 1987, 40: 746-750.

6. Kellaway, G. \& Gardner, D.L. Metastatic reticulum cell sarcoma of the heart causing complete heart block. Scott Med $J$ 1959, 4: 575-580.

7. Cole, T.O., Attah, E.B. \& Onyemelukwe, G.C. Burkitt's lymphoma presenting with heart block. Br Med J 1975, 37: 94-97.

8. Goggio, A.F., Harkness, J.T. \& Palmer, W.S. Stokes-Adams syndrome in Hodgkin's granuloma. JAMA 1961, 176: 687-689. 